\title{
Um estudo sobre eficiência de métodos numéricos para soluções de sistemas lineares
}

\author{
Franciane Fracalossi Rocha* ${ }^{*}$ Etereldes Gonçalves Júnior \\ Universidade Federal do Espírito Santo - Departamento de Matemática \\ Av. Fernando Ferrari, 514, Goiabeiras, Vitória-ES, CEP 29075-910 \\ E-mail: fr.franciane@gmail.com, etereldes@gmail.com.
}

\section{RESUMO}

Resolver sistemas lineares de equações é uma etapa na resolução de problemas científicos tais como os de difusão de calor, elasticidade e mecânica de fluidos. Assim, é importante conhecer alguns métodos de resolução e suas particularidades. Neste trabalho realiza-se uma comparação entre alguns métodos de resolução de sistemas lineares através de análise experimental, onde buscamos a máxima eficiência.

Os métodos numéricos para solução de sistemas lineares é dividido basicamente em duas classes: métodos diretos e métodos iterativos. Os métodos diretos fornecem a solução exata, a menos de erros de arredondamento, após um número finito de operações. Já os iterativos fornecem uma sequência de aproximações da solução, cada uma obtida da anterior pela repetição do mesmo processo. Em outro trabalho, [5], estudamos métodos diretos básicos como o $L U$ parcial e um método de alto desempenho, a transformada rápida de Fourier (FFT). Estes métodos serão comparados com alguns iterativos. A abordagem computacional será usada para implementar e compreender os algoritmos usados na resolução.

Inicialmente estudamos os métodos iterativos clássicos: Jacobi e Gauss-Seidel. Estes métodos resolvem o sistema linear $A x=b$ através de uma decomposição da matriz $A$. Os métodos são parecidos, e foi possível ver que o método de Gauss-Seidel é mais eficiente do que o método de Jacobi pois utiliza melhor as informações obtidas a cada iteração na resolução do sistema linear. Numa comparação destes com os métodos LU parcial e FFT, notamos que os métodos diretos apresentam melhor desempenho.

Em seguida estudamos métodos de projeção: método de máxima descida e método do gradiente conjugado, [1] e [3]. Um processo de projeção é uma maneira canônica de obter uma aproximação para a solução do sistema em um subespaço específico. A solução aproximada $\tilde{x}$ de $A x=b$ é obtida como o ponto de mínimo de um funcional quadrático associado à matriz $A$ positiva definida. $\mathrm{O}$ gradiente conjugado é uma variação do método de máxima descida que utiliza melhor as informações nas iterações.

O modelo usado foi a equação de Laplace com condição de Dirichet na fronteira, discretizada por elementos finitos com funções lineares por elementos e contínuas em todo domínio. O domínio, $D_{1}=$ $[0,1]$ em dimensão um e $D_{2}=[0,1] \times[0,1]$ em dimensão dois, foi dividido formando uma malha uniforme. O gradiente conjugado apresentou-se mais eficiente do que o método de máxima descida. Ambos foram melhor do que o LU parcial, porém não superaram a FFT. Mas a FFT só funciona em malhas estruturadas, [4]. Já o método do gradiente conjugado pode ser usado em malhas mais flexíveis.

O método do gradiente conjugado converge conforme a condição da matriz do sistema. Quanto mais próxima de um a condição $\operatorname{Cond}(A)$ estiver, melhor a convergência. Estudamos então o método do gradiente conjugado precondicionado, onde ao invés de resolver $A x=b$ resolvemos $M^{-1} A x=M^{-1} b$, onde $M$ é simétrica positiva definida. E o número de condição $\operatorname{Cond}\left(M^{-1} A\right)$ é mais próximo de um do que o número de condição $\operatorname{Cond}(A)$. Note que o cálculo de $M^{-1}$ não deve ser muito custoso, [2].

*bolsista de Iniciação Científica PPP/FAPES 
Passamos a estudar precondicionadores de decomposição de domínios. A ideia é decompor o domínio da equação diferencial em subdomínios e a solução nos subdomínios ser utilizada para obter a solução no domínio original. Considere a partição do domínio $D=[a, b]$ em subdomínios disjuntos

$$
\left\{D_{i}=\left(a_{i}, b_{i}\right)\right\}_{i=1}^{N_{S}} \text { com } a=a_{1}<b_{1}=a_{2}<b_{3}<\cdots<b_{N_{S}}=b
$$

onde $N_{S}$ é o número de subdomínios. Esta decomposição é dita sem sobreposição. Com esta decomposição construímos uma nova cobertura $\left\{D_{i}^{\prime}\right\}_{i=1}^{N_{S}}$ do intervalo $D=[a, b]$ com sobreposição $\delta$ definindo

$$
D_{i}^{\prime}=\left\{x \in D \quad \text { tal que } \quad|x-y|<\delta, \quad \text { para algum } y \in D_{i}\right\}=\left(a_{i}-\delta, b_{i}+\delta\right) \cap D .
$$

O precondicionador aditivo de um nível $M_{1}^{-1}$ é definido por $M_{1}^{-1}=\sum_{i=1}^{N_{S}} R^{(i) T}\left[A^{(i)}\right]^{-1} R^{(i)}$. Onde as matrizes $R^{(i)}$ tem apenas papel de alocação e torna-se possível resolver a equação para cada subdomínio. Os precondicionadores aditivos de um nível, que utilizam decomposição de domínio com sobreposição mostraram-se com grande eficiência quando utilizados no método do gradiente conjugado precondicionado. Considere a equação de Laplace com condição de Dirichet no intervalo [0,1]. Dividindo o intervalo $[0,1]$ em $2^{n}$ elementos, alocados em $2^{N}$ subdomínios, temos nas tabelas alguns resultados.

\begin{tabular}{|c|c|}
\hline $\mathrm{n}$ & iterações (condição) \\
\hline 5 & $16(414,3451)$ \\
\hline 6 & $32(1659,4)$ \\
\hline 7 & $64(6639,5)$ \\
\hline 8 & $128(26560)$ \\
\hline
\end{tabular}

Tabela 1: Número de iterações e condição da matriz do gradiente conjugado sem precondicionador.

\begin{tabular}{|c|c|c|c|}
\hline $\mathrm{n} / \mathrm{N}$ & 2 & 3 & 4 \\
\hline 5 & $5(14,4401)$ & $6(26,5320)$ & $9(39,3206)$ \\
\hline 6 & $5(28,2066)$ & $9(53,1851)$ & $10(104,2130)$ \\
\hline 7 & $5(55,5740)$ & $9(105,9159)$ & $17(208,7395)$ \\
\hline 8 & $5(110,2282)$ & $9(211,1029)$ & $17(417,1307)$ \\
\hline
\end{tabular}

\begin{tabular}{|c|c|c|c|}
\hline $\mathrm{n} / \mathrm{N}$ & 2 & 3 & 4 \\
\hline 5 & $6(7,1347)$ & $9(16,4736)$ & $9(39,3206)$ \\
\hline 6 & $6(8,6502)$ & $10(23,3268)$ & $14(63,0262)$ \\
\hline 7 & $6(9,6980)$ & $10(29,4059)$ & $15(89,8513)$ \\
\hline 8 & $6(10,3307)$ & $10(33,8163)$ & $15(114,1032)$ \\
\hline
\end{tabular}

Tabela 2: Número de iterações (condição da matriz) do gradiente conjugado precondicionado com sobreposição de tamanho $\delta=\frac{1}{2^{n}}$ e $\delta=\frac{1}{2^{N}}$ respectivamente.

Foi possível ver a importância dos precondicionadores baseados em decomposição de domínios e o quanto a resolução de um determinado sistema linear pode tornar-se mais eficiente quando os utilizamos. Palavras-chave: Sistemas Lineares, Métodos iterativos, Gradiente Conjugado, Precondicionadores.

\section{Referências}

[1] BIEZUNER, Rodney Josué. Notas de Aula de Álgebra Linear Numérica. Universidade Federal de Minas Gerais, 2009.

[2] GALVIS, J. C. Introdução aos métodos de decomposição de domínio. $27^{\circ}$ Colóqio Brasileiro de Matemática. IMPA, Rio de Janeiro, 2009

[3] GOLUB, Gene H.; LOAN, Charles F. Van. Matrix Computations. 3. ed. Baltimore e Londres: The Johns Hopkins University Press, 1996.

[4] GONÇALVES JÚNIOR, E. A equação de Helmholtz com condições de fronteira de Robbins. Dissertação de mestrado. Universidade Federal Fluminense, 2004.

[5] ROCHA, F. F.; GONCALVES JUNIOR, E. Métodos Numéricos para Solução de Sistemas Lineares e Aplicações (apresentação de trabalho). VI Simpósio Nacional/Jornadas de Iniciação Científica. IMPA, Rio de Janeiro, 2012 